\title{
Desempenho de novilhos mantidos em pastagens de capim-elefante e capim-mombaça
}

\author{
Carolina de Souza Garcia ${ }^{1}$, Alberto Magno Fernandes ${ }^{2}$, Carlos Augusto de Alencar Fontes ${ }^{2,3}$, \\ Ricardo Augusto Mendonça Vieira ${ }^{2}$, Nivaldo de Faria Sant'Ana ${ }^{1}$, Viviane Antunes Pimentel ${ }^{1}$ \\ 1 Pós-Graduação em Ciência Animal - CCTA/UENF. \\ 2 Universidade Estadual do Norte Fluminense Darcy Ribeiro - LZNA/CCTA. \\ ${ }^{3}$ Bolsista do CNPq.
}

RESUMO - Foi avaliado o desempenho de novilhos mantidos em pastagens de capins elefante e mombaça no período de outubro a dezembro de 2006. Adotou-se o sistema de pastejo rotacionado, com oferta regulada de forragem. A área experimental consistia de duas repetições contendo 18 piquetes de 0,25 ha cada, divididos em nove piquetes formados de capim-elefante e nove com mombaça. Os efeitos de tratamentos foram as espécies forrageiras, a repetição de área, a interação entre estes, piquetes dentro da interação e o erro experimental. Este modelo foi usado para analisar os atributos do pasto. Para analisar o consumo, a digestibilidade e o ganho, foram aleatoriamente alocados 24 novilhos para as respectivas interações entre forragem vs. repetição vs. sistema de pastejo, o que totalizou três animais por interação tripla. Os sistemas de pastejo consistiram de pastejo ad libitum (AL) e restrito (PR). O capim-elefante apresentou maior biomassa de matéria seca total (BT) e biomassa de matéria seca verde foliar (BFV). Não houve diferença entre as forrageiras quanto à produção de biomassa de matéria seca verde foliar, no entanto a proporção de folhas foi maior no capim-mombaça. As extrusas apresentaram composição bromatológica semelhante. Apenas o consumo de proteína bruta diferiu entre as forrageiras, sendo este maior para o pasto de mombaça. A alimentação à vontade possibilitou maior consumo de todos os nutrientes em ambas as pastagens. A digestibilidade dos nutrientes foi maior para o capim-elefante, mas não diferiu entre os níveis de alimentação: apenas o teor em proteína bruta foi maior no pasto onde o pastejo foi restrito e o teor de energia bruta do pasto foi maior para o sistema de pastejo à vontade. Apesar das diferenças qualitativas e quantitativas entre as forrageiras, não foram encontradas diferenças quanto ao ganho em peso por animal e por área. Entre os animais com alimentação à vontade, o ganho médio em massa corporal foi de $850 \mathrm{~g} / \mathrm{dia}$ e o ganho por área de $246 \mathrm{~kg} / \mathrm{ha}$ durante o período experimental.

Palavras-chave: consumo, crescimento, digestibilidade

\section{Performance of steers raised on pastures of Elephant and Mombasa grasses}

\begin{abstract}
The performance of steers raised on elephant and mombasa grass pastures was evaluated from October to December 2006. A rotational grazing system with a regulated forage offer was adopted. The experimental area consisted of two repetitions containing 18 0.25-ha paddocks divided into nine paddocks with elephant grass and nine with mombasa grass. Forage species, area repetition, the interaction among these effects, paddocks within the interaction, and the experimental error were the effects of the treatments. This model was used to analyze pasture attributes. For analyses of intake, digestibility and gain, 24 steers were randomly assigned to the respective interactions among forage vs. repetition vs. grazing system, totaling three animals per triple interaction. The grazing systems consisted of ad libitum (AL) and restricted (PR) grazing. Elephant-grass showed the highest total dry matter biomass (TB) and green leaf dry matter biomass (GLDM). There were no differences among forage plants for production of biomass of green leaf dry matter; leaf proportion was the greatest in mombasa grass, however. Extrusas showed similar bromatological composition. Only crude protein intake, which was the highest for mombasa pasture, differed among forage plants. Ad libitum feeding enabled a higher intake of all nutrients from both pastures. Digestibility of nutrients was higher for elephant-grass but it did not differ among feeding levels: only crude protein content was the highest on pasture where grazing was restrict and gross energy content of pasture was higher for ad libitum grazing system. Despite qualitative and quantitative differences among forage plants, differences of weight gain per animal and per area were not found. For animal with ad libitum feeding, average body mass gain was $850 \mathrm{~g} / \mathrm{day}$ and gain per area was $246 \mathrm{~kg} / \mathrm{ha}$ during the experimental period.
\end{abstract}

Key Words: digestibility, growth, intake 


\section{Introdução}

Dotado de características climáticas e extensão territorial favoráveis à pecuária de corte, o Brasil é um dos maiores produtores de carne bovina, possui o maior rebanho comercial do mundo e, nos últimos anos, vem se firmando como o maior exportador de carne.

Entretanto, em consequência da sazonalidade e do valor nutritivo das forrageiras, os animais ficam sujeitos a períodos de ganho (meses chuvosos) alternados a períodos de perda de peso (meses de seca), o que reduz a produtividade dos rebanhos brasileiros de modo geral.

Apesar de o estado do Rio de Janeiro ser um grande importador de carne de outros estados, as regiões norte e noroeste do estado têm condições favoráveis à exploração da pecuária de corte, com solos de boa fertilidade e clima propício e rebanho zebuíno numeroso em relação às demais regiões do estado, porém têm baixa produtividade.

Entre as forrageiras tropicais, destacam-se pela produtividade e pelo valor nutritivo as espécies Pennisetum purpureum e Panicum maximum, com diversos cultivares amplamente utilizados em sistemas de pastejo intensivo, tanto para bovinos leiteiros como para os de corte, por exemplo, os capins elefante, mombaça e tanzânia. Entretanto, devido ao seu hábito de crescimento cespitoso, com rápida elevação dos pontos de crescimento, essas espécies requerem cuidados especiais de manejo para coleta de alta proporção de material (Santos, 1995) de elevado valor nutritivo (Santos et al., 1999), preservação da qualidade do pasto e persistência da pastagem.

Em pastagens, a produtividade animal $(\mathrm{kg} / \mathrm{ha})$ é definida pelo desempenho animal e pela taxa de lotação. O desempenho animal é determinado pela quantidade e qualidade da forragem consumida e pelas características genéticas do animal sob influência do ambiente. Assim, em estudos sobre desempenho animal a pasto, é importante avaliar concomitantemente o consumo e a qualidade da forragem ofertada. A taxa de lotação, comumente expressa em unidade animal ou número de animais por hectare, não indica por si nenhum atributo da pastagem. No entanto, quando associada a uma oferta de forragem préestabelecida, é um indicativo do potencial de produção das pastagens (Roberts, 1980).

Objetivou-se com este estudo avaliar a produção de biomassa, o valor nutritivo, a digestibilidade e o consumo das forrageiras e o desempenho de novilhos em pastagem de Panicum maximum, Jacq. cv. Mombaça, e Pennisetum purpureum, Schum. cv. Napier.

\section{Material e Métodos}

O experimento foi conduzido no município de Campos dos Goytacazes, Rio de Janeiro, situado a $21^{\circ} 44^{\prime} 47^{\prime \prime}$ de latitude sul e a $41^{\circ} 18^{\prime} 24^{\prime \prime}$ de longitude oeste e altitude média de 12 m em relação ao nível do mar. A classificação climática da região segue o padrão $\mathrm{Aw}$ - tropical quente e úmido (Köppen, 1948), com inverno seco e verão chuvoso.

A área experimental, de 9 ha, foi dividida em 36 piquetes de 0,25 ha, igualmente distribuídos entre os capins mombaça e elefante. As repetições de área foram obtidas utilizandose duas repetições por forrageira, com nove piquetes por repetição. Os piquetes foram formados sobre solo aluvial de textura argilosa no ano de 2003. O local não recebia fertilização mineral, adubos orgânicos ou corretivos desde 2005. As forrageiras foram avaliadas, durante o período chuvoso (outubro a dezembro de 2006), em sistema de lotação intermitente precedido por período de adaptação (32 dias) em que os animais foram rotacionados nos piquetes. Os períodos de ocupação e descanso foram de quatro e 28 dias, respectivamente, o que totalizou 32 dias para o ciclo de pastejo e 64 dias para o período experimental total. Anteriormente, ao início do período experimental, procedeu-se à uniformização da área por meio de roçada para atingir a altura do resíduo de pastejo pretendido $(30 \mathrm{~cm})$. Nessa ocasião, foi aplicado superfosfato simples, de acordo com os resultados da análise de solo. Após a uniformização dos piquetes, e sempre após a saída dos animais dos piquetes, foram realizadas adubações de cobertura com sulfato de amônio (50 kg/ha de N) e cloreto de potássio $\left(25 \mathrm{~kg} / \mathrm{ha}\right.$ de $\left.\mathrm{K}_{2} \mathrm{O}\right)$.

As variáveis analisadas foram: biomassa de matéria seca total; biomassa de matéria seca verde foliar; proporção de folhas; taxa de lotação; composição bromatológica e digestibilidade in vitro das extrusas das duas forrageiras.

Foram utilizados 24 novilhos $\mathrm{F}_{1}$ Limousin-Nelore (225 $\pm 38,6 \mathrm{~kg}$ de massa corporal), distribuídos em quatro grupos casualizados nas quatro áreas formadas. Três animais de cada grupo foram designados por sorteio em dois níveis de alimentação: à vontade (pastejo durante todo o dia nos piquetes); e pastejo restrito, com consumo de energia próximo ao de mantença, limitando-se o período de pastejo a 3,5 horas/dia (Fontes et al., 2005). Os animais sob restrição alimentar ficaram alojados em baias individuais com água e suplemento mineral à vontade quando não estavam pastando.

A taxa de lotação foi variável (put and take), mantendo-se a biomassa de matéria seca verde foliar em $5,0 \mathrm{~kg} / 100 \mathrm{~kg}$ de massa corporal para o capim-elefante e $6,5 \mathrm{~kg} / 100 \mathrm{~kg}$ de massa corporal para o capim-mombaça para 
os dois sistemas de pastejo. A biomassa de matéria seca verde foliar foi estimada antes da entrada dos animais nos piquetes.

Foram avaliados os consumos de matéria seca (MS), matéria orgânica $(\mathrm{MO})$, proteína bruta $(\mathrm{PB})$, energia bruta (EB) e fibra em detergente neutro (FDN), em kg de MS/100 kg de massa corporal, e o ganho em massa individual e por unidade de área.

A coleta de dados para avaliação da biomassa disponível foi feita no dia anterior à entrada dos animais em cada piquete, conforme metodologia descrita por Ribeiro et al (2003). A altura do resíduo foi mantida entre 30 e $50 \mathrm{~cm}$ e entre 80 e $100 \mathrm{~cm}$ para os capins mombaça e elefante, respectivamente. A amostragem foi realizada de forma sistemática, em diagonal, retirando-se dez amostras por piquete (40 amostras por hectare), colhendo a forragem contida no quadro metálico $(1 \times 1 \mathrm{~m})$, com corte a $30 \mathrm{~cm}$ do solo.

Da biomassa contida nos quadros, retirou-se uma amostra para obtenção da estimativa de biomassa de MS verde foliar, de modo a orientar o ajuste da carga animal de acordo com metodologia descrita por Ribeiro et al. (2003).

Os dados da análise estatística para biomassa de MS total, biomassa de MS verde foliar e proporção de folhas dos capins mombaça e elefante foram processados de acordo com o modelo:

$$
Y_{i j k}=\mu+F_{i}+R_{j}+F R_{i j}+P_{k(i j)}+e_{i j k},
$$

em que: $\mathrm{Y}_{\mathrm{ijk}}=$ observação referente ao piquete $\mathrm{k}$, da repetição de área $\mathrm{j}$ e forrageira $\mathrm{i} ; \mu=$ média geral; $\mathrm{F}_{\mathrm{i}}=$ efeito da forrageira $i$, em que $i=1 \mathrm{e} 2 ; \mathrm{R}_{\mathrm{j}}=$ efeito da repetição de área $\mathrm{j}$, em que $\mathrm{j}=1,2 ; \mathrm{FR}_{\mathrm{ij}}=$ efeito de interação da forrageira i e da repetição de área $\mathrm{j} ; \mathrm{P}_{\mathrm{k}}(\mathrm{FR})_{\mathrm{ij}}=$ efeito do piquete $\mathrm{k}$, dentro da forrageira i e da repetição de área j, em que $\mathrm{k}=1,2,3$; $\mathrm{e}_{\mathrm{ijk}}=$ erro associado a cada observação, pressuposto normalmente distribuído, com média zero e variância $\sigma^{2}$.

$\mathrm{O}$ termo $\mathrm{P}_{\mathrm{k}(\mathrm{ij})}$ foi utilizado como resíduo na análise dos efeitos de forragem e repetição de área.

O consumo alimentar individual dos novilhos no experimento de desempenho foi estimado ao final do primeiro ciclo de pastejo utilizando-se o método da produção fecal e da indigestibilidade. A produção fecal diária foi estimada utilizando-se o indicador óxido crômico $\left(\mathrm{Cr}_{2} \mathrm{O}_{3}\right)$, fornecido via oral ( $10 \mathrm{~g} / \mathrm{animal} / \mathrm{dia})$, em duas porções de $5 \mathrm{~g}$, às $9 \mathrm{~h} \mathrm{e}$ $15 \mathrm{~h}$, em cartucho de papel, durante 14 dias (sete dias de estabilização e sete dias de coleta). Amostras fecais individuais foram coletadas no reto dos animais no momento de fornecimento do óxido crômico. Ao final de cada dia de coleta, as amostras eram destinadas à secagem em estufa por 72 horas a $60^{\circ} \mathrm{C}$ e moídas para formação de uma amostra composta de fezes por animal, tomando-se $30 \mathrm{~g}$ de MS de cada amostra fecal diária. A concentração de cromo nas fezes foi determinada pelo método colorimétrico após digestão nitroperclórica das amostras, utilizando-se o espectrofotômetro UV visível a $440 \mathrm{~nm}$ (aparelho SPECOL UV visível).

A excreção fecal foi estimada utilizando-se a seguinte fórmula:

Produção fecal $(\mathrm{kg})=\frac{\text { Cromo fornecido }(\mathrm{g})}{\text { Concentração de cromo nas fezes }(\mathrm{g} / \mathrm{kg} \text { de MS })}$

Na estimação do consumo de matéria seca da forragem, foi utilizada a relação excreção fecal/indigestibilidade:

$$
\text { Consumo de MS }(\mathrm{kg})=\frac{\text { Produção fecal } \times 100}{100-\text { digestibilidade da MS }}
$$

Para obtenção de amostras representativas das dietas dos animais em pastejo, foram utilizados dois animais fistulados no esôfago. As coletas de extrusa foram iniciadas no dia anterior ao da coleta de fezes, durante oito dias consecutivos. Nos dias de coleta, os animais fistulados eram privados de alimento 12 horas antes de sua entrada nos piquetes, buscando-se evitar a contaminação das amostras com conteúdo ruminal pela ruminação no momento da coleta (Holecheck, 1982). Em seguida, foram removidas as cânulas esofágicas e colocadas as bolsas de coleta, permitindo aos animais pastejar de 30 a 40 minutos. Os animais fistulados foram mantidos em rodízio nos piquetes ocupados pelos animais experimentais, cada um nas duas repetições de cada forrageira.

As amostras diárias de extrusas foram acondicionadas em sacos plásticos e armazenadas em freezer a $-15^{\circ} \mathrm{C}$. Após o período de coleta das extrusas, a amostras foram secas em estufa por 72 horas a $55^{\circ} \mathrm{C}$, moídas e posteriormente constituíram quatro amostras compostas, uma a cada quatro dias de coleta para cada repetição de forrageira. As amostras compostas foram formadas por $30 \mathrm{~g}$ de MS de cada amostra diária e acondicionadas em frascos de vidro para análises posteriores.

Para estimação do consumo, determinou-se a indigestibilidade considerando a digestibilidade in vitro da extrusa (Tilley \& Terry, 1963), porém em apenas uma etapa.

Foram determinados nas amostras compostas das extrusas e das fezes os teores de matéria seca (MS), matéria orgânica $(\mathrm{MO})$ proteína bruta $(\mathrm{PB})$, energia bruta $(\mathrm{EB})$, além de fibra insolúvel em detergente neutro (FDN), segundo metodologia descrita por Silva \& Queiroz (2002), para estimativa do consumo e da digestibilidade desses nutrientes (Silva \& Queiroz, 2002).

O consumo de energia metabolizável (EM) foi estimado utilizando-se a relação: $\mathrm{EM}=0,82 \times \mathrm{ED}(\mathrm{NRC}, 1996)$.

Para avaliação do ganho de massa corporal, todos os animais experimentais foram pesados a cada 32 dias, depois de jejum de 14 horas. O ganho de massa corporal por área 
foi determinado pelo produto da taxa de lotação média de cada forrageira pelo ganho médio diário dos animais de cada sistema de pastejo multiplicado por 64 (dias de duração do experimento).

$\mathrm{Na}$ análise estatística dos dados de digestibilidade, consumo e ganho de massa corporal dos animais, utilizouse o modelo estatístico:

$Y_{i j k l}=\mu+F_{i}+R_{j}+T_{k}+F R_{i j}+F T_{i k}+R T_{j k}+F R T_{i j k}$ $+\beta_{i j k} \mu_{i j l l} e_{i j k l}$, em que:

$Y_{i j k l}=$ observação referente ao animal $l$, no sistema de pastejo $k$, na forrageira $j$ da repetição de área $i ; \mu=$ média geral; $F_{i}=$ efeito da forrageira $i$, em que $i=1$ e $2 ; R_{j}=$ efeito da repetição de área $\mathrm{j}$, em que $\mathrm{j}=1,2 ; \mathrm{T}_{\mathrm{k}}=$ efeito do sistema de pastejo; $\mathrm{FR}_{\mathrm{ij}}=$ efeito de interação da forrageira i e pastejo $\mathrm{k}$, em que $\mathrm{k}=1$ à vontade e 2 - pastejo restrito; da repetição de área $\mathrm{j} ; \mathrm{FT}_{\mathrm{ik}}=$ efeito de interação da forrageira i e do sistema de pastejo $\mathrm{k} ; \mathrm{RT}_{\mathrm{jk}}=$ efeito de interação da repetição de área $\mathrm{j}$ e do sistema de pastejo $\mathrm{k} ; \mathrm{FRT}_{\mathrm{ijk}}=$ efeito de interação da forrageira $\mathrm{i}$, da repetição de área j e sistema de pastejo $\mathrm{k} ; \beta_{\mathrm{ijk}} \mu_{\mathrm{ijll}}=$ efeito do peso vivo inicial animal 1 , dentro da repetição de área j e do sistema de pastejo k, em que $1=1,2,3 ; \mathrm{e}_{\mathrm{ijkl}}=$ erro associado a cada observação, pressuposto normalmente distribuído, com média zero e variância $\sigma^{2}$.

O termo $\beta_{\mathrm{ijk}} \mu_{\mathrm{ijll}}$ foi utilizado como covariável na análise dos efeitos de repetição de área e do sistema de pastoreio. Os resultados foram submetidos à análise de variância utilizando-se o programa estatístico SAS, procedimento PROC GLM.

\section{Resultados e Discussão}

O capim-elefante apresentou maior $(\mathrm{P}<0,01)$ produção de biomassa total em comparação ao capim-mombaça. A produção de matéria seca foliar não diferiu $(\mathrm{P}>0,05)$ entre as forrageiras, mas a proporção de folhas do capim-mombaça foi maior $(\mathrm{P}<0,01)$ que a do capim-elefante.

Não houve diferenças entre as forrageiras quanto à taxa de lotação (Tabela 1). Maior produção de biomassa total do capim-elefante em relação ao capim-mombaça tem sido relatada por diversos autores: Palieraqui et al. (2006) avaliaram a produtividade dos capins elefantes e mombaça adubados e irrigados durante a seca em regime de lotação intermitente e relataram produções de MS de 5.643 e $2.389 \mathrm{~kg} / \mathrm{ha}$, respectivamente; em avaliação durante as estações seca e chuvosa, Ribeiro et al. (2009) observaram produções de biomassa total de 6.556 e $4.426 \mathrm{~kg} / \mathrm{ha}$ na época seca e de 8.459 e $7.596 \mathrm{~kg} / \mathrm{ha}$ na época chuvosa para os capins elefante e mombaça, respectivamente.
Tabela 1 - Disponibilidade de biomassa e características do dossel

\begin{tabular}{lccc}
\hline \multirow{2}{*}{ Item } & \multicolumn{2}{c}{ Forrageira } & \\
\cline { 2 - 3 } & $\begin{array}{c}\text { Capim- } \\
\text { elefante }\end{array}$ & $\begin{array}{c}\text { Capim- } \\
\text { mombaça }\end{array}$ & $\begin{array}{c}\text { CV } \\
(\%)\end{array}$ \\
\hline Biomassa total $(\mathrm{kg} / \mathrm{ha})$ & $5204 \mathrm{~A}$ & $3457 \mathrm{~B}$ & 38,4 \\
Biomassa de folha verde (kg/ha) & 1995 & 2327 & 33,6 \\
Proporção de folhas (\%) & $36,7 \mathrm{~A}$ & $74,8 \mathrm{~B}$ & 11,15 \\
Taxa de lotação (unidade animal) & 4,4 & 4,6 & 32,12 \\
\hline
\end{tabular}

Médias seguidas de letras maiúsculas diferentes nas linhas diferem a 0,05 de probabilidade.

Os resultados confirmam que o potencial de produção de biomassa total do capim-elefante é superior ao do capimmombaça. De fato, o capim-elefante é considerado uma das espécies forrageiras de maior potencial de produção de biomassa, com produção de matéria seca de até 80 t/ha/ano (Santos, 1995). Todavia, a superioridade do capim-elefante em produção de biomassa total tem sido atribuída ao maior desenvolvimento dos colmos. A predominância do perfilhamento axilar ou lateral proporciona maior elongação do colmo, ao contrário do observado no capim-mombaça, cujo perfilhamento predominante é basal (Parsons, 1988). Por outro lado, essa diferenciação quanto ao hábito de crescimento resulta em maior proporção de folhas no capimmombaça. Assim, a superioridade do capim-elefante em relação ao capim-mombaça é amenizada, ou mesmo anulada, quando se trata da produção de biomassa de folha verde, uma vez que o capim-mombaça apresenta maior proporção de folhas (Ribeiro et al., 2009; Palieraqui et al., 2006). Isso também foi observado neste trabalho, uma vez que a biomassa de folhas verdes não diferiu entre as forrageiras, refletindo a maior $(\mathrm{P}<0,01)$ proporção de folhas do capim-mombaça (Tabela 1).

Em trabalho realizado por Ribeiro et al. (2009), foram verificados valores de altura e densidade volumétrica de $145 \mathrm{~cm}$ e $0,69 \mathrm{~kg} \mathrm{MS} / \mathrm{m}^{3}$ e de $130 \mathrm{~cm}$ e $0,69 \mathrm{~kg} \mathrm{MS} / \mathrm{m}^{3}$ para os capins elefante e mombaça, respectivamente. Os valores referentes à densidade volumétrica não diferiram entre as forrageiras; porém a maior altura observada no capimelefante foi atribuída ao maior porte dessa forrageira. O capim-elefante apresentou maior densidade volumétrica que o capim-mombaça, o que poderia favorecer o consumo dessa forrageira. Entretanto, o capim-mombaça, além de altura mais propícia à apreensão pelos animais, apresentou também maior proporção de folhas (Tabela 1).

A composição bromatológica das forrageiras avaliadas (Tabela 2) encontra-se na faixa de variação observada em estudos anteriores na mesma área: 10 a 14\% de PB; 65 a 77\% de FDN; e 50 a $65 \%$ de digestibilidade in vitro da MS (Palieraqui et al., 2006; Lista et al., 2007; Ribeiro et al., 2009). Os valores observados para a composição bromatológica 
Tabela 2 - Composição das extrusas dos capins elefante e mombaça

\begin{tabular}{lcc}
\hline & \multicolumn{2}{c}{ Forrageira } \\
\cline { 2 - 3 } & $\begin{array}{c}\text { Capim- } \\
\text { elefante }\end{array}$ & $\begin{array}{c}\text { Capim- } \\
\text { mombaça }\end{array}$ \\
\hline Matéria orgânica (\% MS) & 90,6 & 90,6 \\
Proteína bruta (\% MS) & 11,7 & 12,2 \\
Fibra detergente neutro (\% MS) & 69,5 & 67,4 \\
Lignina (\% MS)1 & 4,1 & 3,8 \\
DIVMS (\%) & 58,9 & 55,9 \\
\hline
\end{tabular}

${ }^{1}$ Lignina determinada em ácido sulfúrico.

de ambas as forrageiras não parecem limitantes à digestão da fibra em nível de rúmen (Van Soest, 1994), o que refletiu no ganho alcançado pelos animais.

Os consumos de matéria seca, energia metabolizável e fibra em detergente neutro não diferiram $(\mathrm{P}>0,05)$ entre as forrageiras, exceto o de proteína bruta, que foi maior nos animais alocados nos piquetes de capim-mombaça. No nível de alimentação à vontade, o consumo de todos os nutrientes foi superior ao observado nos animais sob restrição alimentar, fato já esperado. Não houve efeito de interação $(\mathrm{P}>0,05)$ forrageira $\times$ nível de alimentação sobre o consumo de nutrientes das forrageiras (Tabela 3 ).

A fraca evidência de variação nos consumos de matéria seca das duas forrageiras não pode ser explicada exclusivamente pela maior digestibilidade de MS e FDN do capim-elefante (Tabela 4). No entanto, o consumo de pasto não é influenciado somente pelo valor nutritivo da forragem, mas também por fatores como biomassa, estrutura da pastagem e ambiente (Carvalho et al., 2001) e pela interação entre o pasto e o animal que o consome (Ellis et al., 1999).

Em pesquisa com os capins mombaça e elefante em regime de lotação intermitente nas épocas chuvosa e seca, Ribeiro et al. (2008) relataram maior consumo de forragem em novilhos pastejando capim-elefante na época chuvosa. Palieraqui et al (2006), em condições experimentais semelhantes às relatadas por Ribeiro et al. (2008), observaram que o consumo de capim-mombaça foi maior que o de capimelefante na época seca do ano.

Em valores absolutos, Palieraqui et al. (2006) verificaram para novilhos mestiços em pastagens de capim-elefante e capim-mombaça, na ausência e presença de irrigação, variações no consumo de 2,9 a 3,3\% do PV. Em experimento com novilhos nelores em pastagens cultivadas com três cultivares de Panicum, Brâncio et al. (2003) observaram consumos de 1,9 a 3,4\% do peso vivo (PV), dependendo da época do ano avaliada. Menores valores de consumo, variando entre 1,7 a $1,9 \%$ do $\mathrm{PV}$, foram obtidos por Cândido et al. (2005) em pastagens de capim-mombaça.

Tabela 3 - Consumo de nutrientes em pastagens de capim-elefante e capim-mombaça sob pastejo restrito e à vontade

\begin{tabular}{|c|c|c|c|c|}
\hline \multirow[b]{2}{*}{ Item } & \multicolumn{2}{|c|}{ Nível de alimentação } & \multirow[b]{2}{*}{ Média } & \multirow[b]{2}{*}{$\mathrm{CV}(\%)$} \\
\hline & À vontade & Restrito & & \\
\hline Matéria seca (kg/animal/dia) & & & & 13,8 \\
\hline Capim-mombaça & 9,2 & 5,0 & $7,1 \mathrm{a}$ & \\
\hline Média & $9,0 \mathrm{~A}$ & $4,6 \mathrm{~B}$ & & \\
\hline Matéria orgânica (kg/animal/dia) & & & & 13,8 \\
\hline Média & $8,1 \mathrm{~A}$ & $4,2 \mathrm{~B}$ & & \\
\hline Proteína bruta (kg/animal/dia) & & & & 13,8 \\
\hline Capim-elefante & 1,03 & 0,50 & $0,76 \mathrm{a}$ & \\
\hline Capim-mombaça & 1,12 & 0,61 & $0,87 \mathrm{~b}$ & \\
\hline Média & $1,07 \mathrm{~A}$ & $0,55 \mathrm{~B}$ & & \\
\hline Fibra detergente neutro (kg/animal/dia) & & & & 13,8 \\
\hline Capim-elefante & 6,1 & 2,9 & $4,5 \mathrm{a}$ & \\
\hline Capim-mombaça & 6,2 & 3,4 & $4,8 \mathrm{a}$ & \\
\hline Média & $6,1 \mathrm{~A}$ & $3,1 \mathrm{~B}$ & & \\
\hline Matéria seca (\% PV/dia) & & & & 15,4 \\
\hline Capim-elefante & 2,9 & 1,6 & $2,3 \mathrm{a}$ & \\
\hline Capim-mombaça & 3,2 & 2,0 & $2,6 \mathrm{a}$ & \\
\hline Média & $3,0 \mathrm{~A}$ & $1,8 \mathrm{~B}$ & & \\
\hline
\end{tabular}

Médias seguidas de letras maiúsculas diferentes nas linhas e minúsculas nas colunas diferem entre si a $0,05 \%$ de probabilidade. 
Tabela 4 - Digestibilidade dos componentes de capim-elefante e capim-mombaça sob pastejo restrito e à vontade

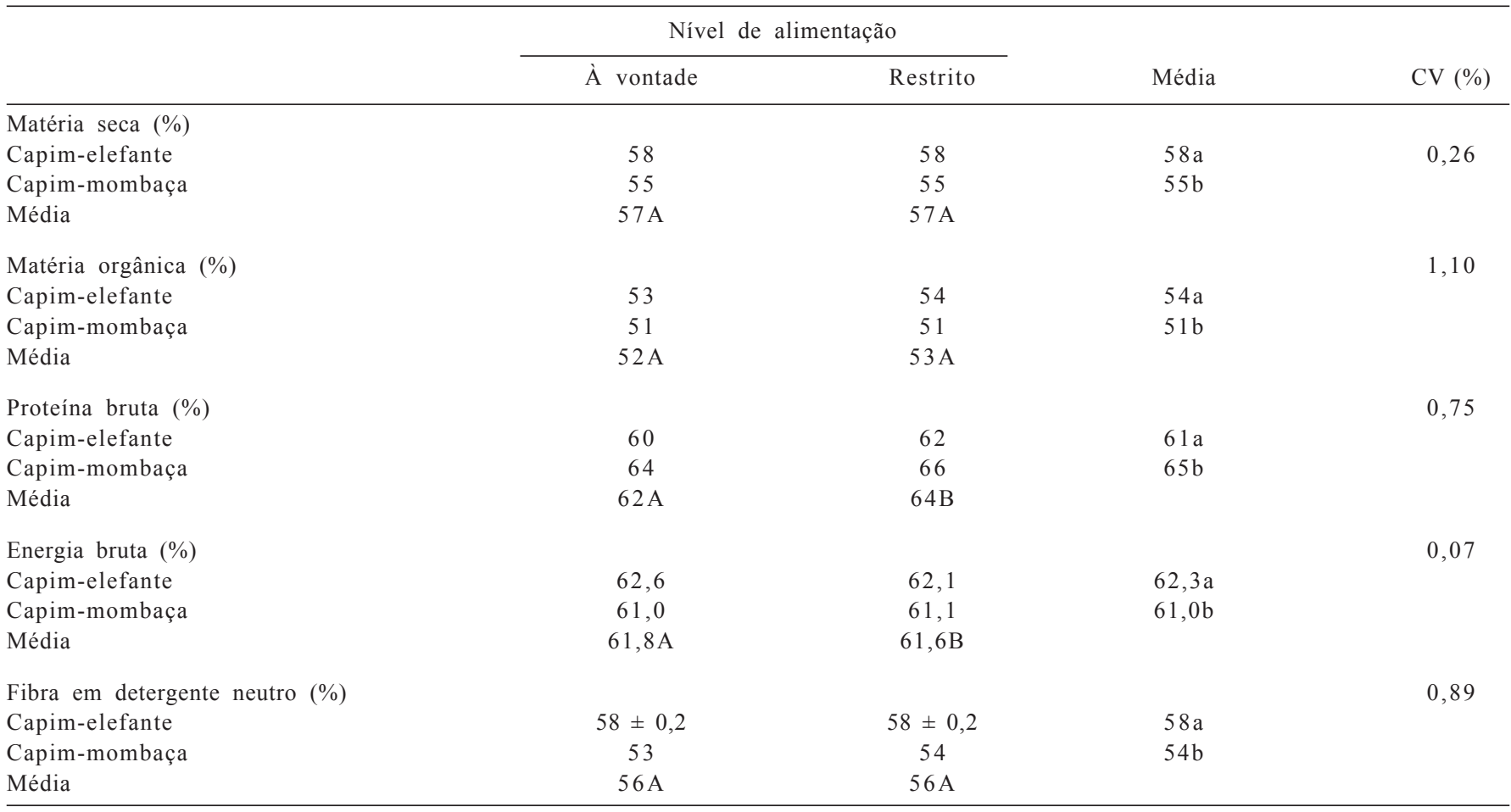

Médias seguidas de letras maiúsculas diferentes nas linhas e minúsculas nas colunas diferem a $0,05 \%$ de probabilidade.

Neste trabalho, para os animais sob alimentação à vontade, foi observado consumo médio de 3,0\% do PV, que está de acordo com os relatados na literatura (Brâncio et al., 2003; Cândido et al., 2005; Palieraqui et al., 2006).

Em comparação ao capim-mombaça, o capim-elefante apresentou maior digestibilidade de matéria seca, matéria orgânica, energia bruta e fibra em detergente neutro. A digestibilidade de $\mathrm{PB}$ foi maior nos animais sob restrição alimentar, enquanto a de energia bruta foi maior naqueles alimentados à vontade. A digestibilidade de MS, MO e FDN não diferiu entre os níveis de alimentação nem foi afetada pela interação combinação $(\mathrm{P}>0,05)$ entre forrageira e nível de alimentação (Tabela 4).

No caso da digestibilidade da PB, a superioridade do capim-mombaça pode estar relacionada à maior proporção de folhas (Tabela 1) dessa forrageira, que apresenta praticamente o dobro de folhas do capim-elefante. É nas folhas que se encontra a maior proporção de tecidos de maior digestibilidade (Akin, 1989), portanto é de se esperar maior digestibilidade também da proteína bruta.

O consumo do animal tem sido associado negativamente à digestibilidade do alimento (ARC, 1980; NRC, 2001). O efeito do consumo sobre a digestibilidade estaria relacionado à taxa de passagem dos resíduos indigeríveis ao longo do trato gastrintestinal (Mertens \& Ely, 1979). No entanto, neste trabalho não foi observado efeito do nível de alimentação sobre a digestibilidade das forrageiras.

Segundo o NRC (2001), a redução da digestibilidade de acordo com o consumo é proporcionalmente maior para dietas mais digestíveis e deve ser desconsiderada no caso de dietas com coeficientes de digestibilidade inferiores a 0,60 . De fato, a menor digestibilidade da dieta desfavorece o consumo, tendo em vista a limitação física do rúmen para processamento do alimento (Van Soest, 1994). Nesse sentido, a digestibilidade média da matéria seca verificada neste trabalho, abaixo de 0,60 , explicaria a ausência do efeito do nível alimentar.

O ganho de peso diferiu entre os sistemas de alimentação, pois foi maior nos animais do sistema de pastejo à vontade, no entanto, não apresentou diferenças entre as forrageiras, tanto quando calculado por animal quanto por área (Tabela 5), provavelmente porque não houve variações no consumo dessas forrageiras (Tabela 4).

Resultados inferiores aos obtidos neste trabalho foram observados, nas mesmas condições, em pesquisas conduzidas na época chuvosa com novilhos mantidos em pastagens de capim-mombaça e capim-elefante adubadas e manejadas em lotação intermitente: de $0,62 \mathrm{~kg} / \mathrm{dia}$; 5,0 animais $/$ ha e $432 \mathrm{~kg} / \mathrm{ha}$, respectivamente, para ganho de peso, taxa de lotação e ganho por área (Erbesdobler et al., 2002; Alexandrino et al., 2005; Cândido et al., 2005). 
Tabela 5 - Desempenho dos animais em pastejo nos capins elefante e mombaça ${ }^{1,2}$

\begin{tabular}{lccc}
\hline & \multicolumn{2}{c}{ Nível de alimentação } & Média \\
\cline { 2 - 3 } Item & À vontade & Restrito & CV $(\%)$ \\
\hline Ganho de peso médio (kg/animal/dia) ${ }^{1}$ & 0,85 & 0,32 & 28,41 \\
Capim-elefante & 0,85 & 0,14 & $0,59 \mathrm{a}$ \\
Capim-mombaça & $0,85 \mathrm{~A}$ & $0,23 \mathrm{~B}$ & $0,50 \mathrm{a}$ \\
Média & & & $166 \mathrm{a}$ \\
Ganho de peso por área (kg/ha) & & 90 & $146 \mathrm{a}$ \\
Capim-elefante & 242 & 41 & 28,41 \\
Capim-mombaça & 250 & $66 \mathrm{~B}$ & \\
Média & $246 \mathrm{~A}$ & \\
\hline
\end{tabular}

${ }^{1}$ Animais com peso vivo inicial médio de $225,0 \mathrm{~kg}$.

2 Ganho de peso total em 64 dias.

Médias seguidas de letras maiúsculas diferentes nas linhas e minúsculas nas colunas diferem a $0,05 \%$ de probabilidade

\section{Conclusões}

Os capins elefante e mombaça apresentam diferenças significativas de digestibilidade de alguns nutrientes como a matéria orgânica e a fibra, além de diferenças como o número de folhas. Entretanto, não há evidência experimental que comprove a existência de diferenças entre os desempenhos de bovinos mantidos em pastagens dessas forrageiras durante o período chuvoso do ano na região norte fluminense. Em circunstâncias de criação semelhantes às encontradas no presente experimento, espera-se um ganho em peso médio de $850 \pm 240 \mathrm{~g} / \mathrm{d}$ para animais mestiços Limousin-Nelore, o que implica em ganho por área de $246 \pm 70 \mathrm{~kg} / \mathrm{ha}$.

\section{Referências}

AKIN, D.E. Histological and physical factors affecting digestibility of forages. Agronomy Journal, v.81, p.17-25, 1989.

ALEXANDRINO, E.; GOMIDE, C.A.M.; CÂNDIDO, M.J.D. et al. Período de Descanso, Características Estruturais do Dossel e Ganho de Peso Vivo de Novilhos em Pastagem de CapimMombaça sob Lotação Intermitente. Revista Brasileira Zootecnia, v.34, n.6, p.2174-2184, 2005.

AGRICULTURAL RESEARCH COUNCIL - ARC. The nutrient requirements of ruminants. London, $1980.351 \mathrm{p}$.

BRÂNCIO, P.A.; NASCIMENTO JUNIOR, D.; EUCLIDES, V.P.B. Avaliação de três cultivares de Panicum Maximum Jacq. sob pastejo: composição da dieta, consumo de matéria seca e ganho de peso animal. Revista Brasileira de Zootecnia, v.32, n.5, p.1037-1044, 2003.

CÂNDIDO, M.J.D.; ALEXANDRINO, E.; GOMIDE, C.A.M. et al. Período de descanso, valor nutritivo e desempenho animal em pastagem de Panicum maximum cv. Mombaça sob lotação intermitente. Revista Brasileira Zootecnia, v.34, n.5, p.1459-1467, 2005.

CARVALHO, P.C.F.; RIBEIRO FILHO, H.M.N.; POLI, C.E.C. et al. Importância da estrutura da pastagem na ingestão e seleção de dietas pelo animal em pastejo. In: REUNIÃO ANUAL DA SOCIEDADE BRASILEIRA DE ZOOTECNIA, 38., 2001, Piracicaba. Anais... Piracicaba: Sociedade Brasileira de Zootecnia, p.853-871, 2001.
ELLIS, W.C.; POPPI, D.P.; MATIS, J.H. et al. Dietary-digestive-metabolic interactions determining the nutritive potential of ruminant diets. In: JUNG, H.J.G.; FAHEY JUNIOR, G.C. (Eds.) Nutritional ecology of herbivores. Savoy, Illinois, 1999. p.423-481.

ERBESDOBLER, E.D.; FONTES, C.A.A.; QUEIROZ, D.S. et al. Avaliação do consumo e ganho de peso de novilhos em pastejo rotacionado de capim-elefante (Penissetum purpureum, Schum.) cv. Napier, na estação chuvosa. Revista Brasileira de Zootecnia, v.31, n.5, p.2123-2128, 2002.

FONTES, C.A.A.; OLIVEIRA, R.C.; ERBESDOBLER, E.D. et al. Conteúdo de energia líquida para mantença e ganho do capimelefante e mudanças na composição corporal de novilhos em pastejo, durante a estação chuvosa. Revista Brasileira de Zootecnia, v.34, n.5, p.1711-1720, 2005.

HOLECHECK, J.L.; VAVRA, M.; PIEPER, R.D. Methods for determining the nutritive quality of range ruminants diets: A Review. Journal of Animal Science, v.54, p.363-375, 1982.

KÖPPEN, W. Climatologia. Buenos Aires: Gráfica Panamericana, 1948. $478 \mathrm{p}$.

LISTA, F.N.; SILVA, J.F.C.; VASQUEZ, H.M. et al. Avaliação de métodos de amostragem qualitativa em pastagens tropicais manejadas em sistema rotacionado. Revista Brasileira Zootecnia, v.36, n.5, p.1413-1418, 2007.

MERTENS, D.R.; ELY, L.O. A dynamic model of fiber digestion and passage in the ruminant for evaluating forage quality. Journal Animal Science, v.49, p.1085-1095, 1979.

NATIONAL RESEARCH COUNCIL - NRC. Nutrients requeriments of dairy cattle. 8.ed. Washington, D.C.: National Academy Press, 2001. 242p.

PALIERAQUI, J.G.B.; FONTES, C.A.A.; RIBEIRO, E.G. et al. Influência da irrigação sobre a disponibilidade, a composição química, a digestibilidade e o consumo dos capins mombaça e napier. Revista Brasileira Zootecnia, v.35, n.6, p.2381-2387, 2006.

PARSONS, A.J. The effect of season and management on the growth of grass swards. In: JONES, M.B.; LAZEMBY, A. (Eds.). The grass crops: the physiological basis of production. London: Chapman \& Itall, 1988. p.129-177.

RIBEIRO, E.G.; FONTES, C.A.A.; PALIERAQUI, J.G.B., et al., Influência da irrigação, durante as épocas seca e chuvosa, na taxa de lotação, consumo e desempenho de novilhos em pastagens dos capim-elefante e capim-mombaça. Revista Brasileira de Zootecnia, v.37, n.9, p.1546-1554, 2008.

RIBEIRO, E.G. et al. Influência da irrigação, nas épocas seca e chuvosa, sobre a produção e a composição química dos capins Napier e Mombaça submetidos lotação intermitente. Revista Brasileira de Zootecnia, v.38, n.8, p.1432-1442, 2009.

RIBEIRO, E.G.; FONTES, C.A.A.; PALIERAQUI, J.G.B. et al Estimação do teor de matéria seca e disponibilidade de forrageiras tropicais por intermédio do método de microondas. In: REUNIÃO ANUAL DA SOCIEDADE BRASILEIRA DE ZOOTECNIA, 40., 2003, Santa Maria. Anais... Santa Maria: SBZ, 2003. (CD-ROM) 
ROBERTS, C.R. Effect of stocking rate on tropical pastures. Tropical Grasslands, v.14, n.3, p.225-231, 1980.

SANTOS, P.M.; CORSI, M.; BALSALOBRE, M.A.A. Efeito da freqüência de pastejo e da época do ano sobre a produção e a qualidade em Panicum maximum cvs. Tanzânia e Mombaça. Revista Brasileira de Zootecnia, v.28, n.2, p.244-249, 1999.

SANTOS, F.A.P. Manejo de pastagem de capim-elefante. In: PEIXOTO, A.M.; MOURA, J.C.; FARIA, V.P. (Eds). Volumoso para bovinos. 2.ed. Piracicaba: FEALQ, 1995. p.1-20.
SILVA, D.J.; QUEIROZ, A.C. Análise de alimentos (métodos químicos e biológicos). 2.ed. Viçosa, MG: Universidade Federal de Viçosa, 2002. 235p.

TILLEY, J.M.A.; TERRY, R.A.A. Two stage technique for in vitro digestion of forage crops. Journal of British Grassland Society, v.18, n.2, p.104-111, 1963.

VAN SOEST, P.J. Nutritional ecology of the ruminant. 2.ed. London: Comstock Publishing Associates - Cornell University Press, 1994. 476p. 